\title{
Treatment Outcome of Severe Acute Malnutrition and Its Determinants among Pediatric Patients in West Ethiopia
}

\author{
Muluken Berhanu Mena, ${ }^{1}$ Mohammed Gebre Dedefo $\left(\mathbb{D},{ }^{2}\right.$ and Bruke Berhanu Billoro ${ }^{3}$ \\ ${ }^{1}$ Bitena Primary Hospital, Wolaita, Ethiopia \\ ${ }^{2}$ Department of Pharmacy, Wollega University, Nekemte, Ethiopia \\ ${ }^{3}$ Department of Pharmacy, Wachemo University, Hossana, Ethiopia
}

Correspondence should be addressed to Mohammed Gebre Dedefo; mohamedg@wollegauniversity.edu.et

Received 2 March 2018; Revised 30 June 2018; Accepted 18 July 2018; Published 30 July 2018

Academic Editor: Seng Hock Quak

Copyright (C) 2018 Muluken Berhanu Mena et al. This is an open access article distributed under the Creative Commons Attribution License, which permits unrestricted use, distribution, and reproduction in any medium, provided the original work is properly cited.

\begin{abstract}
Background. Malnutrition is a silent killer that is underreported, underaddressed, and as a result underprioritized. It is reported that severe acute malnutrition is the commonest reason for pediatrics hospital admission in many poor countries; 25 to $30 \%$ of children with severe malnutrition die during hospital admissions. Objective. To determine treatment outcome of severe acute malnutrition and identify its determinants among pediatric patients in pediatrics ward of Nekemte Referral Hospital. Methods. A retrospective hospital-based cross-sectional study was done from November 2015 to April 2017. Data had been collected by using checklist for recording information from patient card and register book. Association between independent variables and depend variable was assessed using bivariate and stepwise multivariable logistic regression, respectively. Level of statistical significance was declared at $\mathrm{p}$ value $<0.05$. Results. Out of 205 admitted children with severe acute malnutrition, $137(66.8 \%)$ cases were cured from SAM, $9(4.4 \%)$ cases were died because of SAM, and (16.6\%) cases were defaulter from SAM management, and 25 (12.2\%) cases were transferred out. Multivariable logistic regression showed that children admitted with both edema and wasting AOR $=8.30,95 \% \mathrm{CI}$ $(1.72,40.09) \mathrm{P}=0.008$, children without hypothermia $\mathrm{AOR}=2.91,95 \% \mathrm{CI}(1.10,7.69) \mathrm{P}=0.031$, children who stay $8-14$ days $\mathrm{AOR}=$ $3.86,95 \% \mathrm{CI}(1.01,14.75) \mathrm{P}=0.048$, children without pneumonia $\mathrm{AOR}=7.82,95 \% \mathrm{CI}(2.74,222.29) \mathrm{P}=0.001$, children without anemia $\mathrm{AOR}=3.22,95 \% \mathrm{CI}(1.04,9.97) \mathrm{P}=0.042$, and children without $\mathrm{HIV} \mathrm{AOR}=9.21,95 \% \mathrm{CI}(2.20,38.54) \mathrm{P}=0.002$ were more likely to be cured from severe acute malnutrition. Conclusion. Treatment outcome of severe acute malnutrition in this study is good. It shows that around three-fourths of the children were cured. Factors such as admission criteria, hypothermia, length of stay, pneumonia, anemia, and presence of HIV were associated with treatment response.
\end{abstract}

\section{Introduction}

Malnutrition is a broad term commonly used as an alternative to undernutrition but technically it also refers to overnutrition. In this study the term malnutrition refers to undernutrition. Malnutrition and malnourishment are synonyms of undernutrition and undernourishment, respectively [1]. Severe Acute Malnutrition (SAM) is defined as weight-forheight ratio of less than minus 3 standard deviations below the median reference population or weight-for-height ratio of below $70 \%$ or presence of nutritional edema [2].

Malnutrition is a silent killer that is underreported, underaddressed, and as a result underprioritized. Every hour and minute of every day, 300 and 5 children die due to malnutrition respectively. In the world today, one child in four is stunted because of malnutrition, and in underdeveloped countries this figure is as high as one in three and specifically in Africa two out of five children will suffer from malnutrition [3].

Worldwide, it is estimated that there are nearly 20 million children who are severely acutely malnourished. The majority of those affected are found in South Asia and Sub-Sahara Africa. Approximately one million children die every year from severe acute malnutrition [2]. Greater than $25 \%$ of children under five in the developing world are undernourished which accounts about 143 million children. Among these 143 million malnourished children, almost three-quarters live in just 10 countries in Sub-Saharan Africa region and more 
than one-quarter of children under five are undernourished (Nigeria and Ethiopia alone account for more than 33\%) [4].

A study conducted in Nigeria showed that $9 \%$ of children hospitalized for severe malnutrition were HIV infected [5]. Malnutrition is multifactorial and HIV can induce or aggravate it. In Sub-Saharan Africa, mortality is higher in HIV infected children and ranges from $25 \%$ to $38 \%$ with severe malnutrition than in noninfected children $[5,6]$. During renutrition, mortality was still found to be higher in HIV positive than HIV negative children in Malawi $[7,8]$.

In a severely malnourished child who has diarrhea, mortality is high ranging from $67.3 \%$ to $71 \%$ and the cause of death is commonly due to dehydration and electrolytes imbalances. Death is also associated with septicemia, pneumonia, malaria, and hypothermia [6, 9-11].

One way or in another way, malnutrition contributes to $53 \%$ of deaths of children under five in developing countries. According to the United Nations International children's Emergency Fund (UNICEF) estimates, around 26 million under-five children suffer from SAM in developing country [12]. Ethiopia is one of the countries with the highest underfive child mortality rate, with malnutrition underlying to $57 \%$ of all children deaths [13].

The latest Ethiopia Mini Demography and Health Survey stated that stunting, wasting, and underweight among underfive children in Ethiopia are $40 \%, 9 \%$, and $25 \%$, respectively, and this figure is very high compared to national figure in Somali region $(38.4 \%, 27.0 \%$, and $38.8 \%)$, respectively [14].

This study therefore aimed at determining the treatment outcome and the predictors of poor treatment response among undernourished children admitted to Nekemte Referral Hospital where there is paucity of this important data. The findings of this study intend to further aid clinicians to improve the outcome of these children.

\section{Methods}

2.1. Study Setting and Study Period. The study was conducted in Nekemte Referral Hospital (NRH), Nekemte town, Eastern Wollega zone, Oromia National Regional State, which is located at $331 \mathrm{~km}$ from Addis Ababa. NRH was established in 1932 (1924 EC) by Swedish mission. Hospital catchment population is $2,028,680$. It has different departments and wards like outpatient department (OPD), medical ward, gynecology and obstetrics ward, pediatrics ward, and surgical ward. It delivers diversified health services and clinics including the emergency services, eye clinic, dental clinic, mother child health $(\mathrm{MCH})$, psychiatry clinic, laboratory, radiology, pharmacy, physiotherapy, and followup of chronic diseases. The pediatric ward of NRH had 46 beds. The study was conducted from March 1/2017 to April 1/2017.

2.2. Study Design. This study was a retrospective hospitalbased cross-sectional study.

2.3. Study Population. All malnourished pediatric patients who had been admitted to inpatient pediatric ward of $\mathrm{NRH}$ from November 2015 to April 2017 and fulfilled inclusion criteria were included in this study.
2.4. Inclusion and Exclusion Criteria. In this study malnourished children with age from 1 month to 14 years and children with a known treatment outcome who were admitted to pediatrics ward were included while children who were discharged within 24 hours and participants with incomplete data were excluded.

2.5. Sample Size. Two hundred and five (205) patients diagnosed with severe acute malnutrition and admitted to pediatrics ward from November 2015 to April 2017 and who fulfilled inclusion criteria were studied.

2.6. Data Collection Method and Data Quality Control. The data were collected through medical record reviews of pediatric patients, by using a prepared checklist. A checklist addressed all needed information as a data collection tool. Before starting the data collection, data collecting format was cross-matched with available information on records; then the study checklist and weight-for-height chart had been rearranged as necessary. Incomplete chart had been discarded. Data collections were conducted with appropriate training of the data collectors and continuous advices to keep the quality of the data. Close supervision was made by the investigators and the collected data were checked for completeness every day.

2.7. Data Processing and Analysis. Data were entered into the Statistical Package for the Social Sciences (SPSS) version 20 for analysis. Both bivariate and multivariate analyses were done by using binary logistic regression. Variables those having association in binary logistic regression was checked by multivariate logistic regression to identify confounders. A bivariate analysis was carried out to see the association between dependent and independent variables. All variables with $\mathrm{p}$ value $<0.25$ were taken to multivariable model to control all possible confounders odds ratio along with $95 \%$ confidence level which was estimated to identify factors associated with the outcome of variable using multivariable logistic regression analysis. Level of statistical significance was declared at $\mathrm{p}$ value $<0.05$ levels.

2.8. Ethics Approval and Consent to Participate. Ethical clearance was obtained from the Ethical Review Committee of Wollega University, College of Health Sciences. This committee has also written a formal letter of permission to Nekemte Referral Hospital to permit accessing the data and cooperate. The Nekemte Referral Hospital also rechecked for ethical compatibility and permitted the data access. As the study was conducted through a review of records, no consent was obtained from the mothers or caregivers of the study subjects. The confidentiality of study participants was secured. In addition all data were kept confidential.

\section{Results}

3.1. Sociodemographic and Admission Information. From all admitted children, 138 (67.3\%) were under five years of age and $67(32.7 \%)$ of them were between five to fifteen 
TABLE 1: Distribution of demographic and admission information on treatment outcome of children with SAM admitted to NRH, West Ethiopia from November 2015 to April 2017 ( $n=205)$.

\begin{tabular}{|c|c|c|c|}
\hline Variables & Categories & Frequency & Percentages (\%) \\
\hline \multirow{4}{*}{ Age } & 1month-1 year & 38 & 18.5 \\
\hline & $>1$ year- 5 years & 100 & 48.8 \\
\hline & $>5$ years- 10 years & 36 & 17.6 \\
\hline & $>10$ years- 14 years & 31 & 15.1 \\
\hline \multirow{2}{*}{ Sex } & Female & 107 & 52.2 \\
\hline & Male & 98 & 47.8 \\
\hline \multirow{2}{*}{ Place of residence } & Urban & 45 & 22.0 \\
\hline & Rural & 160 & 78.0 \\
\hline \multirow{3}{*}{ Weight for height or weight for length } & $<70 \%$ & 76 & 37.1 \\
\hline & $70-85 \%$ & 101 & 49.3 \\
\hline & $>85 \%$ & 28 & 13.7 \\
\hline \multirow{3}{*}{ MUAC at admission } & $<110 \mathrm{~mm}$ & 159 & 77.6 \\
\hline & $111-120 \mathrm{~mm}$ & 32 & 15.6 \\
\hline & $>120 \mathrm{~mm}$ & 14 & 6.8 \\
\hline \multirow{3}{*}{ MUAC at discharge } & $<110 \mathrm{~mm}$ & 34 & 16.6 \\
\hline & $111-120 \mathrm{~mm}$ & 153 & 74.6 \\
\hline & $>120 \mathrm{~mm}$ & 18 & 8.8 \\
\hline \multirow{2}{*}{ Admission type } & New admission & 194 & 94.6 \\
\hline & Re-admission & 11 & 5.4 \\
\hline \multirow{4}{*}{ Admission criteria } & only edema or kwashiorkor & 36 & 17.6 \\
\hline & only wasting or marasmus & 89 & 43.4 \\
\hline & both edema and wasting & 66 & 32.2 \\
\hline & MUAC & 14 & 6.8 \\
\hline \multirow{5}{*}{ Child is referred from } & Hospital & 32 & 15.6 \\
\hline & OPD & 158 & 77.1 \\
\hline & Outreach & 5 & 2.4 \\
\hline & SFC & 5 & 2.4 \\
\hline & Spontaneous & 5 & 2.4 \\
\hline \multirow{4}{*}{ Length of stay } & $\leq 7$ days & 23 & 11.2 \\
\hline & 8-14 days & 102 & 49.8 \\
\hline & 15-22 days & 58 & 28.3 \\
\hline & $\geq 23$ days & 22 & 10.7 \\
\hline
\end{tabular}

years. From the total children admitted with severe acute malnutrition, 107 (52.2\%) were females and 98 (47.8\%) were males. Most of the children, 194 (94.6\%), were identified as newly admitted children and $11(5.4 \%)$ of them were readmission. Among 205 children, 160 (78.0\%) were from rural and most of the admitted children in the program were referred from outpatient department (158) (77.1\%). Of the total children, $89(43.4 \%)$ were admitted because of marasmus (wasted) and 36 (17.3\%) Kwashiorkor (edematous); 66 (32.2\%) were presented with both marasmus and kwashiorkor and $14(6.8 \%)$ of them were admitted because of MUAC (Table 1).

3.2. Medical Comorbidities. Of all admitted children, more than three-fourths $(3 / 4)$ of pediatric patients' appetite at admission was poor (158) (77.1\%). The most common medical comorbidities accompanied with SAM children at time of admission were anemia (146) (71.2\%), followed by vomiting
(82) (40.0\%), fever (78) (38.0\%), and diarrhea (72) (35.1\%) (Table 2).

3.3. Treatment Given. Management of children admitted with severe acute malnutrition to pediatrics ward was based on the Federal Ministry of Health of Ethiopia Guideline Protocol for treatment of severe acute malnutrition. Out of 205 children whose medication records were available for review, the most prescribed medications were (137) (66.8\%) paracetamol, (114) (55.6\%) folic acid, and (110) (53.7\%) antibiotic, while the least prescribed was (99) (48.3\%) measles vaccine (Table 3 ).

3.4. Treatment Outcome. Out of 205 admitted children with severe acute malnutrition, 137 (66.8\%) cases were cured from SAM, 9 (4.4\%) cases died because of SAM, 34 (16.6\%) cases were defaulter from SAM management, and $25(12.2 \%)$ cases were transferred out from pediatric ward of NRH (Table 4). 
TABLE 2: Distribution of medical comorbidities information on treatment outcome of children with SAM admitted to Pediatric Ward of NRH, West Ethiopia, from November 2015 to April 2017 ( $n=205)$.

\begin{tabular}{lcc}
\hline Variables & Frequency & Percentages (\%) \\
\hline Fever & 78 & 38.0 \\
Hypothermia & 60 & 29.3 \\
Appetite at admission & 47 & 22.9 \\
$\quad$ Good & 158 & 77.1 \\
$\quad$ Poor & 44 & 21.5 \\
Pneumonia & 82 & 40.0 \\
Vomiting & 72 & 35.1 \\
Diarrhea & & \\
Types of diarrhea $(\mathrm{n}=72)$ & 66 & 91.7 \\
$\quad$ Watery & 6 & 8.3 \\
$\quad$ Dysentery & & 88.9 \\
Duration of diarrhea $(\mathrm{n}=72)$ & 64 & 11.1 \\
$\quad$ Acute & 8 & 10.2 \\
$\quad$ Persistent & 21 & 7.8 \\
Presence of HIV & 16 & 14.6 \\
Presence of TB & 30 & 71.2 \\
presence of malaria & 146 & 33 \\
Anemia & &
\end{tabular}

TABLE 3: Distribution of treatment given information on treatment outcome for children with SAM admitted to NRH, West Ethiopia, from November 2015 to April 2017 ( $\mathrm{n}=205)$.

\begin{tabular}{|c|c|c|c|}
\hline Variables & Categories & Frequency & Percentages (\%) \\
\hline \multirow{3}{*}{ Antibiotic given } & Yes & 110 & 53.7 \\
\hline & No & 63 & 30.7 \\
\hline & not indicated & 32 & 15.6 \\
\hline \multirow{3}{*}{ Vitamin A } & Yes & 102 & 49.8 \\
\hline & No & 57 & 27.8 \\
\hline & not indicated & 46 & 22.4 \\
\hline \multirow{3}{*}{ measles vaccine } & Yes & 99 & 48.3 \\
\hline & No & 56 & 27.3 \\
\hline & not indicated & 50 & 24.4 \\
\hline \multirow{3}{*}{ Fully Immunized } & Yes & 47 & 22.9 \\
\hline & No & 59 & 28.8 \\
\hline & not indicated & 99 & 48.3 \\
\hline \multirow{3}{*}{ Folic acid } & Yes & 114 & 55.6 \\
\hline & No & 27 & 13.2 \\
\hline & not indicated & 64 & 31.2 \\
\hline \multirow{3}{*}{ Albendazole/Mebendazole } & Yes & 94 & 45.9 \\
\hline & No & 70 & 34.1 \\
\hline & not indicated & 41 & 20.0 \\
\hline \multirow{3}{*}{ Paracetamol } & Yes & 137 & 66.8 \\
\hline & No & 53 & 25.9 \\
\hline & not indicated & 15 & 7.3 \\
\hline
\end{tabular}

3.5. Determinants of Treatment Outcome. To know determinants of treatment outcome, the treatment response of the child was classified into two categories as cured and not cured. Not cured includes dyinh and defaulter. Transferring out was excluded because of difficulty to know their treatment outcome. When 25 of the participants were excluded the total sample size to analyze remains 180; from them 137 (76\%) were cured and $43(24 \%)$ were not cured. 
TABLE 4: Distribution of treatment outcome for SAM children who were admitted to NRH, West Ethiopia, from November 2015 to April 2017 $(\mathrm{n}=205)$.

\begin{tabular}{|c|c|c|c|}
\hline Variables & Categories & Frequency & Percent (\%) \\
\hline \multirow{4}{*}{ Treatment response of the child } & Died & 9 & 4.4 \\
\hline & Cured & 137 & 66.8 \\
\hline & defaulter & 34 & 16.6 \\
\hline & Transferred out & 25 & 12.2 \\
\hline \multirow{2}{*}{ Weight gain for cured in $\mathrm{kg}(\mathrm{n}=137)$} & Yes & 130 & 94.9 \\
\hline & No & 7 & 5.1 \\
\hline \multirow{4}{*}{ Length of days the child stays for cured $(\mathrm{n}=137)$} & $\leq 7$ days & 4 & 2.9 \\
\hline & 8-14 days & 60 & 43.8 \\
\hline & 15-22 days & 55 & 40.1 \\
\hline & $\geq 23$ days & 18 & 13.1 \\
\hline \multirow{2}{*}{ MUAC gain for cured in $\mathrm{mm}(\mathrm{n}=137)$} & Yes & 130 & 94.9 \\
\hline & No & 7 & 5.1 \\
\hline
\end{tabular}

TABLE 5: Results of binary and multivariable logistic regression analysis indicating determinants of treatment outcome of children admitted to pediatric ward of NRH by SAM from November 2015 to April 2017 ( $\mathrm{n}=205)$.

\begin{tabular}{|c|c|c|c|c|c|}
\hline \multirow[t]{2}{*}{ Variables } & \multirow{2}{*}{ Categories } & \multicolumn{2}{|c|}{ Treatment response of the child } & \multirow{2}{*}{$\operatorname{COR}(95 \% \mathrm{CI})$} & \multirow[t]{2}{*}{$\operatorname{AOR}(95 \% \mathrm{CI}) \mathrm{p}$-value } \\
\hline & & Not cured (\%) & Cured (\%) & & \\
\hline \multirow{4}{*}{ Admission criteria } & $\begin{array}{l}\text { Only edema or } \\
\text { kwashiorkor }\end{array}$ & $11(6.1)$ & 20(11.1) & 1.00 & 1.00 \\
\hline & $\begin{array}{l}\text { Only wasting or } \\
\text { marasmus }\end{array}$ & $24(13.3)$ & $56(31.1)$ & $1.28(0.53,3.08)$ & $1.25(0.34,4.63) \mathrm{P}=0.733$ \\
\hline & Both edema and wasting & $5(2.8)$ & $50(27.8)$ & $5.50(1.69,17.85)$ & $8.30(1.72,40.09) \mathrm{P}=0.008$ \\
\hline & MUAC & $3(1.7)$ & $11(6.1)$ & $2.01(0.46,8.80)$ & $0.96(0.14,6.39) \mathrm{P}=0.968$ \\
\hline \multirow{2}{*}{ Fever } & Present & $21(11.6)$ & $42(23.3)$ & 1.00 & 1.00 \\
\hline & Absent & $22(12.2)$ & $95(52.8)$ & $2.15(1.07,4.34)$ & $2.48(0.89,6.90) \mathrm{P}=0.082$ \\
\hline \multirow{2}{*}{ Hypothermia } & Present & $17(9.4)$ & $32(17.8)$ & 1.00 & 1.00 \\
\hline & Absent & $26(14.4)$ & $105(58.3)$ & $2.14(1.03,4.44)$ & $2.91(1.10,7.69) \mathrm{P}=0.031$ \\
\hline \multirow{4}{*}{ Length of stay } & $\leq 7$ days & $12(6.8)$ & $9(5)$ & 1.00 & 1.00 \\
\hline & 8-14 days & $19(10.5)$ & $63(35)$ & $4.42(1.61,12.07)$ & $3.86(1.01,14.75) \mathrm{P}=0.048$ \\
\hline & 15-22 days & $7(3.9)$ & $48(26.7)$ & $9.14(2.82,29.54)$ & $10.93(2.18,54.68) \mathrm{P}=0.004$ \\
\hline & $\geq 23$ days & $5(2.8)$ & $17(9.4)$ & $4.53(1.21,16.96)$ & $2.53(0.48,13.16) \mathrm{P}=0.270$ \\
\hline \multirow{2}{*}{ Pneumonia } & Present & $19(10.5)$ & $15(8.3)$ & 1.00 & 1.00 \\
\hline & Absent & $24(13.3)$ & $122(67.7)$ & $6.43(2.87,14.41)$ & $7.82(2.74,22.29) \mathrm{P}=0.001$ \\
\hline \multirow{2}{*}{ Anemia } & Yes & $34(18.8)$ & $91(50.5)$ & 1.00 & 1.00 \\
\hline & No & $9(5)$ & $46(25.5)$ & $1.91(0.84,4.31)$ & $3.22(1.04,9.97) \mathrm{P}=0.042$ \\
\hline \multirow{3}{*}{ Presence of HIV } & Yes & $9(5)$ & $9(5)$ & 1.00 & 1.00 \\
\hline & No & $16(8.8)$ & $79(43.8)$ & $4.93(1.69,14.37)$ & $9.21(2.20,38.54) \mathrm{P}=0.002$ \\
\hline & unknown & $18(10)$ & $49(27.2)$ & $2.72(0.93,7.93)$ & $6.92(1.63,29.27) \mathrm{P}=0.009$ \\
\hline
\end{tabular}

Regarding treatment outcome of each SAM type, for patients with only edema or kwashiorkor of the total 31 patients $20(64.5 \%)$ were cured from SAM, for patients with only wasting or marasmus of the total 80 patients $56(70 \%)$ were cured from SAM, and for patients with both edema and wasting of the total 55 patients 50 (90.9\%) were cured from SAM (Table 5).

The bivariable analysis showed that admission criteria, fever, hypothermia, length of stay, pneumonia, anemia, and presence of HIV were associated with treatment response.
However, other factors like age, sex, place of residence, weight-for-height, admission type, appetite admission, vomiting, diarrhea, presence of TB, presence of malaria, sever superficial infection, and all routine medications do not show any significant association with treatment response of the child (Table 5).

Variables with $\mathrm{P}$ value $<0.25$ like age, sex, place of residence, appetite at admission, vomiting, diarrhea, and presence of TB entered multivariable. The results of multivariable logistic regression showed that children admitted with both 
edema and wasting are 8.3 times more likely to be cured than child admitted by only edema in $\mathrm{AOR}=8.30,95 \% \mathrm{CI}$ $(1.72,40.09) \mathrm{P}=0.008$. Children without hypothermia are 2.91 times more likely to be cured than children with hypothermia $\mathrm{AOR}=2.91,95 \% \mathrm{CI}(1.10,7.69) \mathrm{P}=0.031$. Children who stay 8 14 days are 3.86 times more likely to recover or cured than children who stay $\leq 7$ days $\mathrm{AOR}=3.86,95 \% \mathrm{CI}(1.01,14.75)$ $\mathrm{P}=0.048$. Children without pneumonia are 7.82 times more likely to be cured than children with pneumonia in $\mathrm{AOR}=$ 7.82 , 95\%CI $(2.74,222.29) \mathrm{P}=0.001$. Children without anemia are 3.22 times more likely to be cured AOR $=3.22$, 95\%CI $(1.04,9.97) \mathrm{P}=0.042$. The children without $\mathrm{HIV}$ were 9.21 times more likely to have positive outcome AOR $=9.21,95 \%$ CI $(2.20,38.54) \mathrm{P}=0.002$ (Table 5).

\section{Discussion}

The finding of this study showed that, of the study participants with severe acute malnutrition and with known outcome, $76 \%$ were cured. Better achievement was recorded in improving treatment outcome as compared to studies conducted in Lusaka, Zambia (53.7\%), Kamba, south west Ethiopia (67.7\%), Tigray (61.7\%), and Jimma (45\%) [6, 1517]. However treatment response was poor as compared to similar study conducted from southern Bangladesh (92\%), Mardi Niger (91.4\%), south Ethiopia (Wolaita (92\%), kembata tembaro (92\%), and Sidamo zone (94.3\%)) [18-22]. In this study achieving low treatment response may be because of inappropriate management of children such as partial prescription of routine medication and due to medical comorbidity at admission such as presence of pneumonia and HIV.

Children admitted with both edema and wasting were identified as positive predictors of treatment response. Similar to this study different study conducted in Harari, Ghana, and Uganda revealed that patients without edema were less likely to recover from SAM [23-25].

The treatment outcome of this study showed that children who stayed 8-14 days $(\mathrm{p}=0.048)$ and $15-22$ days $(\mathrm{p}=0.004)$ had better outcome as compared to children who stayed $\leq 7$ days. Similar to this study a study conducted in Southern Ethiopia [26] reported that children with SAM who stayed longer had achieved recovery criteria.

A study conducted in Tigray health facility reported that the most administered medications were antibiotics (72.13\%) and vitamin A (59.17\%) while the least was folic acid which was administered to only $5.89 \%$ and multivariable analysis showed that taking antibiotics and deworming drugs were positive predictors to recovery rate from SAM. But, having diarrhea, vomiting, and loss of appetite were negative predictors to recovery rate from SAM [15]. However, in this finding the most administered medications were paracetamol (66.8\%), folic acid (55.6\%), and antibiotics. Different from the study conducted in Tigray [15], the present finding showed that no significant association was seen between treatment outcome and taking antibiotics and deworming. However the present study showed significant association between positive treatment outcome and absence of anemia $(p=0.042)$ and hypothermia $(\mathrm{p}=0.031)$.
A study conducted in Yakatit 12 Hospital in Addis Ababa showed that of all the severely malnourished children (24.3\%) have pneumonia, (11\%) have tuberculosis, and (21\%) have diarrhea [27]. Comparable with this, this study showed that from children who were admitted with SAM (21.5\%) have pneumonia, (7.8 \%) have tuberculosis, and (35.1\%) have diarrhea.

The study conducted in Chad on data-analysis revealed that significant associations were found between not cured and diarrhea [7]. Different to this research; the finding of this study did not showed significant association with diarrhea but significant association were seen between high cure rate and absence of HIV $(p=0.002)$ and pneumonia $(\mathrm{p}=0.001)$.

This study has its own limitation. The study only used the recorded data of the discharged children to measure treatment outcomes and associated factors. Therefore, this study has limitation in measuring the effect of factors such as education and economic status of parents and completing data on breast feeding. In addition to that there are some factors which had no statistical association with the treatment outcome in this study which may affect the precision. Eventually, users are recommended to take all these into account during interpretation of the findings and degree of precision.

\section{Conclusion}

Treatment outcome of severe acute malnutrition in this study is good. It shows that around thre-fourths of the children were cured. Factors such as admission criteria, hypothermia, length of stay, pneumonia, anemia, and presence of HIV were associated with treatment response. Majority of the admitted children have marasmus type of malnutrition. To improve treatment outcome for children with severe acute malnutrition, continuous supervision has to be done for healthcare professionals to avoid irrational provision of routine medication and attention should be given for improving the capacity of healthcare professionals on proper management of severe acute malnutrition. In addition to this comorbid diseases have to be treated appropriately to increase cure rate.

\section{Data Availability}

The data used to support the findings of this study are available from the corresponding author upon request.

\section{Conflicts of Interest}

The authors declare that they have no conflicts of interest.

\section{Acknowledgments}

Authors wish to thank Wollega University for funding this research. Authors also wish to acknowledge Nekemte Referral Hospital staff for their support in helping to facilitate the activities of the study and data collectors.

\section{References}

[1] World Health Organization, Management of severe malnutrition: a manual for physicians and other senior health workers. 1999. 
[2] World health organization, the world food program, the united nations standing committee on nutrition \&amp; united nations children's fund. Community-based management of Severe Acute Malnutrition. Geneva. 2007.

[3] Save the children international, A life free from hunger: "Tackling Child Malnutrition," Geneva. 2012.

[4] UNICEF. Children and the Millennium Development Goals. Progress for children a report card on nutrition. 2007.

[5] H. Bachou, J. K. Tumwine, R. K. N. Mwadime, and T. Tylleskär, "Risk factors in hospital deaths in severely malnourished children in Kampala, Uganda," BMC Pediatrics, vol. 6, article no. 7, 2006.

[6] A. H. Irena, M. Mwambazi, and V. Mulenga, "Diarrhea is a major killer of children with severe acute malnutrition admitted to inpatient set-up in Lusaka, Zambia," Nutrition Journal, vol. 10, no. 1, article no. 110, 2011.

[7] Ruwan Ratnayake, Casie Tesfar \& Mark Myatt. Determining predictors for severe acute malnutrition: Causal analysis with in a SQUEAC assessment in Chad. 2012.

[8] C. Schofield and A. Ashworth, "Why have mortality rates for severe malnutrition remained so high?" Bulletin of the World Health Organization, vol. 74, no. 2, pp. 223-229, 1996.

[9] R. E. Black, S. Cousens, H. L. Johnson et al., "Global, regional, and national causes of child mortality in 2008: a systematic analysis," The Lancet, vol. 375, no. 9730, pp. 1969-1987, 2010.

[10] O. A. Uthman, "Using extended concentration and achievement indices to study socioeconomic inequality in chronic childhood malnutrition: The case of Nigeria," International Journal for Equity in Health, vol. 8, 2009.

[11] C. Dubray, S. A. Ibrahim, M. Abdelmutalib et al., "Treatment of severe malnutrition with 2-day intramuscular ceftriaxone vs 5-day amoxicillin," Annals of Tropical Paediatrics, vol. 28, no. 1, pp. 13-22, 2008.

[12] M. Kerac, "Routine antibiotics given for uncomplicated severe acute malnutrition reduce mortality and improve nutritional recovery," Evidence Based Medicine, vol. 19, no. 1, pp. el-e1, 2014.

[13] Federal Ministry of Health. Decentralization and scale up of outpatient management of SAM in Ethiopia. 2011.

[14] CSA/ORC. Ethiopian demographic and health survey 2005, Addis Ababa, Ethiopia and Calverton, Maryland, USA: Central statistics Authority and OCR Macro, 2006.

[15] HG. Yobyo, C. Kendall, D. Nigusse, and W. Lemma, "Outpatient Therapeutic Feeding Program Outcomes and Determinants in Treatment of Severe Acute Malnutrition in Tigray, Northern Ethiopia," PLoS ONE, vol. 8, no. 6, Article ID 0065840, 2013.

[16] N. M. Dale, M. Myatt, C. Prudhon, and A. Briend, "Using Mid-Upper Arm Circumference to End Treatment of Severe Acute Malnutrition Leads to Higher Weight Gains in the Most Malnourished Children," PLoS ONE, vol. 8, no. 2, Article ID e55404, 2013.

[17] N. A. Shanka and S. Lemma, "Recovery Rate and Determinants in Treatment of Children with Severe Acute Malnutrition using Outpatient Therapeutic Feeding Program in Kamba District, South West Ethiopia," Journal of Nutritional Disorders \& Ther$a p y$, vol. 5, no. 2, 2015.

[18] A. Tekeste, M. Wondafrash, G. Azene, and K. Deribe, "Cost effectiveness of community-based and in-patient therapeutic feeding programs to treat severe acute malnutrition in Ethiopia," Cost Effectiveness and Resource Allocation, vol. 10, 2012.
[19] E. Teferi, M. Lera, S. Sita, Z. Bogale, D. G. Datiko, and M. A. Yassin, "Treatment outcome of children with severe acute malnutrition admitted to therapeutic feeding centers in Southern Region of Ethiopia," Ethiopian Journal of Health Development, vol. 24, no. 3, pp. 234-238, 2010.

[20] I. Defourny, E. Drouhin, M. Terzian, M. Tatay, and J. Sekkenes, Scaling up the treatment of acute childhood malnutrition in Niger. 2006.

[21] K. Sadler, C. Puett, G. Mothabbir, and M. Myatt, Community Case Management of Severe Acute Malnutrition in Southern Bangladesh, Feinstein International Center: Tufts University, Bangladesh, 2011.

[22] M. Eklund and T. Girma, Effectiveness of Integrated Outpatient Care of Severe Acute Malnutrition in Ethiopia, 2008.

[23] M. M. Mengesha, N. Deyessa, B. S. Tegegne, and Y. Dessie, "Treatment outcome and factors affecting time to recovery in children with severe acute malnutrition treated at outpatient therapeutic care program," Global Health Action, vol. 9, no. 1, p. 30704, 2016.

[24] M. Saaka, S. M. Osman, A. Amponsem et al., "Treatment outcome of severe acute malnutrition cases at the tamale teaching hospital," Journal of Nutrition and Metabolism, vol. 2015, 2015.

[25] R. Nyeko, V. Calbi, B. O. Ssegujja, and G. F. Ayot, "Treatment outcome among children under-five years hospitalized with severe acute malnutrition in St. Mary's hospital Lacor, Northern Uganda," BMC Nutrition, vol. 2, no. 1, 2016.

[26] E. Tadesse, ntegrated community-based management of severe acute child malnutrition. Studies from rural Southern Ethiopia. Digital Comprehensive Summaries of Uppsala Dissertations from the Faculty of Medicine 1232. 2016. 62 pp. Uppsala: Acta Universitatis Upsaliensis. ISBN 978-91-554-9601-2.

[27] T. T. Gelaw, "Response to Conventional Nutritional Treatment of Severely Malnourished Hospitalized Children in the Context of HIV Infection at Yekatit 12 Hospital, Addis Ababa, Ethiopia," Science Journal of Clinical Medicine, vol. 2, no. 6, p. 176, 2013. 


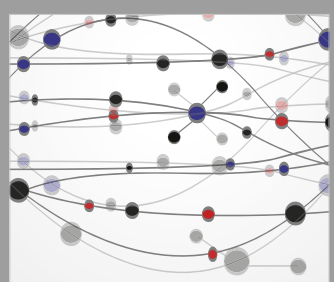

The Scientific World Journal
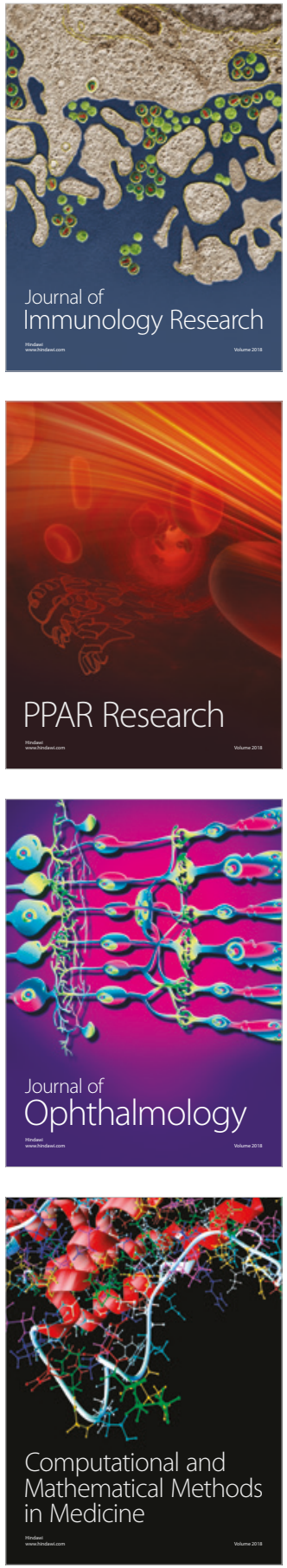

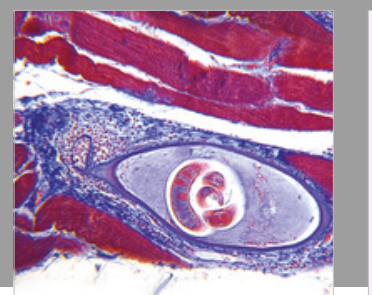

Gastroenterology Research and Practice

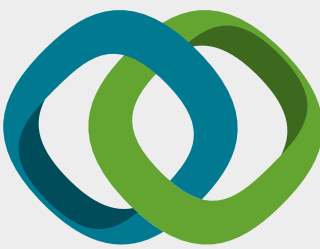

\section{Hindawi}

Submit your manuscripts at

www.hindawi.com


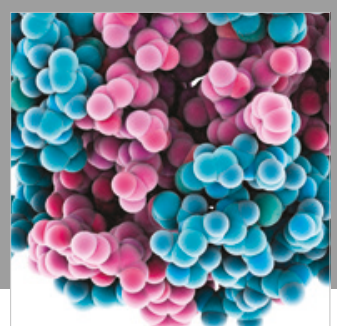

ournal of

Diabetes Research

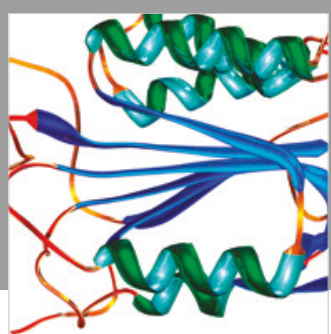

Disease Markers
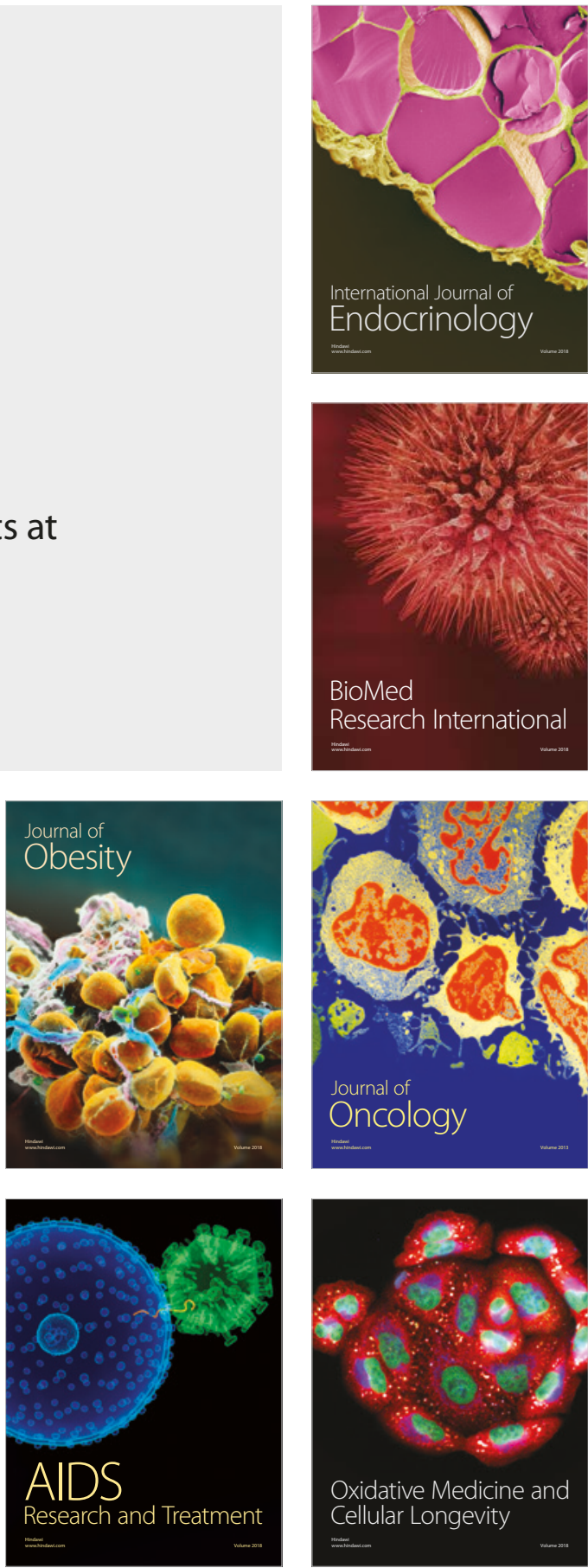